\title{
Domestic mammals facilitate tick-borne pathogen transmission networks in South African wildlife
}

Marcela P.A. Espinaze ${ }^{\mathrm{a}, \mathrm{b}, *}$, Eléonore Hellard ${ }^{\mathrm{a}}$, Ivan G. Horak ${ }^{\mathrm{c}}$, Graeme S. Cumming ${ }^{\mathrm{a}, \mathrm{d}}$

\footnotetext{
${ }^{a}$ Percy FitzPatrick Institute, DST-NRF Centre of Excellence, University of Cape Town, Private Bag X3, Rondebosch 7701, South Africa

${ }^{\mathrm{b}}$ Department of Conservation Ecology and Entomology, Private Bag X1, Stellenbosch University, Matieland 7602, South Africa

${ }^{c}$ Department of Veterinary Tropical Diseases, Faculty of Veterinary Science, University of Pretoria, Private Bag X04, Onderstepoort 0110, South Africa

${ }^{\mathrm{d}}$ ARC Centre of Excellence for Coral Reef Studies, James Cook University, Townsville, Queensland 4811, Australia

* Corresponding author at: Department of Conservation Ecology and Entomology, Private Bag X1, Stellenbosch University, Matieland 7602, South Africa. E-mail address: mespinaze@ @un.ac.za (M.P.A. Espinaze).
}

\section{Highlights}

- The high connectivity of South African mammals by ticks facilitates pathogen transmission.

- Domestic animals enhance the spread of pathogens among South African mammal species.

- Conservation practices that mingle domestic and wild mammals increase the risk of disease.

\begin{abstract}
As changes in the environment have brought wild and domestic animals into closer proximity, crossspecies disease transmission has become a major concern in wildlife conservation. In Africa, livestock are often kept on the edges of protected areas and frequently share habitat with wild animals. Many tick (Acari: Ixodidae) species can feed successfully on both domestic and wild mammals; and by
\end{abstract}


feeding on different hosts at different life stages, can transmit pathogens between them. The influence of the composition of the host community on pathogen transmission by ticks remains poorly understood, however, making it difficult to determine whether sharing habitats with domestic livestock increases tick-borne disease in populations of wild animals. We used network analysis to analyse 35,349 collections of 54 tick species in South Africa, treating hosts as nodes and shared tick species as links. Across all life stages, 93 mammalian host species were connected by a total of 3,105 edges. Sheep, goats, and dogs emerged as particularly important domestic species for network connectivity; and for wild animals, soft-skinned, smaller mammals such as the scrub hare. Although some South African ticks show some degree of specialization on wild animals, network analysis showed that opportunistic feeding on domestic hosts can lead to shortened transmission pathways and facilitate pathogen spread between mammal species. Mammal species are highly interconnected through the tick species that they share, and domestic mammals significantly increase the risk of disease transmission. These findings support conservation management measures that limit contact between domestic and wild mammals to reduce tick-borne disease transmission. Proposals to allow local communities grazing access to protected areas must be carefully evaluated in light of the increased disease risks to both domestic and wild animals, and potentially also to people.

\section{Keywords:}

Wild mammal species; Domestic animals; Host-parasite dynamics; Cross-species transmission; Disease control; Ixodid ticks 


\section{Introduction}

Infectious diseases are an important and growing concern for conservation, with changes in disease prevalence, diversity, and severity occurring rapidly as the earth's environment is changed by people. Cross-species disease transmission and the (re)emergence of pathogens from wild reservoirs are often facilitated by anthropogenic activities (Antia et al. 2003; Lubroth 2012). Climate change, for example, can alter the geographic distribution of arthropod vectors, augmenting the risk of infectious disease transmission in wild species and the incidence of zoonoses in humans (Cumming \& Van Vuuren 2006; Garamszegi 2011). Human activities and associated landscape changes are bringing domestic animals, wild animals and humans into increasingly closer proximity in many places, resulting in reciprocal exchanges of pathogens (Pastoret et al. 1988; Daszak et al. 2001; Patz et al. 2004; Prager et al. 2012a; Hegglin et al. 2015; Han et al. 2016; Hassell et al. 2017). In southern Africa, the wildlife trade and wildlife translocations into conservation and hunting areas near livestock ranches and rural subsistence communities further increase such contacts, in addition to causing stress and undermining the immune systems of wild animals (Karesh et al. 2005; Penzhorn 2006; Chomel et al. 2007). As a result, the increasing anthropogenic alteration of natural environments offers numerous opportunities for generalist pathogens and cross-species pathogen transmission, with negative implications for wildlife, protected areas, and human health (Dobson \& Foufopoulos 2001; Altizer et al. 2003; De Vos et al. 2016).

Although wild animals were historically considered natural reservoirs of many infectious diseases of domestic animals (Taylor \& Martin 1987), transmission from domesticated species to sympatric wildlife has become a major problem for conservation (Daszak et al. 2000; Daszak et al. 2001; Prager et al. 2012a). Over a quarter of domestic mammal pathogens are infectious to wildlife species (Cleaveland et al. 2001). For example, canine distemper outbreaks recorded in lion populations in the Serengeti National Park were initiated by domestic dogs, but also affected silver-backed jackals, bat- 
eared foxes, and African wild dogs (Roelke-Parker et al. 1996; Prager et al. 2012b). Livestock parasites that are shared with African wildlife include rinderpest between cattle and African buffalo, eland and greater kudu; brucellosis between cattle and African buffalo and hippopotamus; foot and mouth disease between cattle and African buffalo; African swine fever between domesticated swine and the common warthog; and bovine tuberculosis between cattle and African buffalo, greater kudu, common duiker and lechwe (Pastoret et al. 1988).

The complexity of the problem of understanding the relative influences of wild and domestic hosts on parasite and pathogen dynamics is increased by host generalism. Many parasites and pathogens can infect multiple host species (Woolhouse et al. 2001; Keesing et al. 2006). The generalist capacity of such pathogens has been linked to pathogen genetic variability and abundant opportunities for cross-species transmission (Woolhouse et al. 2001). However, multi-host pathogen dynamics in host communities remain poorly understood. Previous studies have shown that host species diversity can affect the prevalence of some pathogens, whilst infectious diseases can in turn influence host community structure (Power \& Mitchell 2004; Keesing et al. 2006). Multi-host-multi-parasite systems are complex, but it is clear that within these systems, all species are not equal. Some hosts may be particularly susceptible to infection, and some vectors may be particularly good at transmitting particular pathogens. Epidemic disease outbreaks, for example, often arise via a reservoir species which maintains a relatively high pathogen population and from which pathogens spill over to other hosts (Daszak et al. 2000; Power \& Mitchell 2004).

In this paper, we explore the roles of wild and domestic mammalian hosts in transmission networks for tick-borne pathogens in South Africa. In particular, we were interested in how alternative conservation approaches, and particularly those that mix wildlife and domestic stock versus those that keep them separate, may affect the potential for exchanges of ticks and tick-borne pathogens. The feeding behaviour of ticks on different host species creates a system of multiple interconnections that 
can be viewed as a network, in which hosts are linked by the ticks they share (Caron et al. 2012). Previous studies that have used network analysis to examine the dynamics of parasite infections between individuals of the same host species (Godfrey et al. 2009; Godfrey et al. 2010; MacIntosh et al. 2012) have shown that higher levels of network connectivity tend to increase individual risk of infection and that some parasites may enhance transmission opportunities through their influence on host behaviour (Godfrey et al. 2009). Networks of contacts between different host species and their consequences for pathogen dynamics in multi-species systems have been less investigated, but have the potential to make important contributions to our understanding of multi-host parasite and pathogen transmission pathways (Jeger et al. 2007; Olesen et al. 2008; Salathé \& Jones 2010; Pilosof et al. 2015).

We undertook network analysis of an extensive new dataset of 35349 tick-host interactions to assess the connectivity between 93 South African mammal hosts (85 wild mammals and eight domestic mammals) based on the tick species that they share. We used the analysis to identify the most highly connected hosts that facilitate potential tick-borne disease transmission, and explore the likely effects of domestic species on these associations. We hypothesised (H1) that since many South African ticks show some degree of specialization on wild animals but feed freely on domestic hosts (Cumming 1998; Cumming 1999; Espinaze et al. 2016), adding domestic species to the network should shorten transmission pathways (i.e., by providing shorter routes between different species) and facilitate the spread of pathogens. Alternatively (H2), if ticks were wildlife specialists or pure generalists, adding domestic hosts should have little impact on the spread of pathogens because doing so would either not add new connections to the network or because the network would be highly interconnected independently of the presence of domestic species. 


\section{Material and methods}

\subsection{Data}

The dataset used in this study results from 36 years of tick collection by [co-author's name] in South Africa. Each tick sampled was either collected from a dead (natural death, roadkill, hunted) or a living or slaughtered host (domestic species). A total of 35349 collections (a collection is defined as occuring whenever one or more ticks of a given species were obtained from a single host) of 54 tick species (from eight genera, family Ixodidae) (Supporting Information), obtained from 93 mammal host species (85 wild mammals and eight domestic mammals) (Supporting Information) were included in the analyses. For each collection, the tick species, life stage (larva, nymph or adult), number of individual ticks collected, mammalian host species, host health condition, geographic location of the sample, and date of collection were recorded. Occasionally the host species was not known, but its genus or family was indicated (e.g. Genetta sp. for genets). Hosts that have been included belonged to 11 orders of mammals: Carnivora (29 spp.), Cetartiodactyla (30 spp.), Rodentia (14 spp), Primates (3 spp.), Perissodactyla (6 spp.), Macroscelidea (4 spp.), Lagomorpha (3 spp.), Proboscidea (1 sp.), Hyracoidea (1 spp.), Eulipotyphla (1 spp.), and Soricomorpha (1 family, Soricidae).

\subsection{Network construction}

Mammal host species were represented as nodes (vertices) in the network, and tick species shared by pairs of hosts were represented as edges (links). Edges were weighted by the numbers of different tick species shared by each pair of hosts. Since all mammals could work as both donors and recipients of pathogens, the network system was considered "undirected" (Proulx et al. 2005; Poulin 2010). Tick host specificity varies with life-stage (Espinaze et al. 2016), and so three networks were built: a network of hosts sharing all ticks (regardless of life stage), a network of hosts sharing juvenile (i.e., larva and nymph) ticks, and a network of hosts sharing adult ticks. The matrices matching all possible 
pairs of hosts and the tick species they shared were generated using SQL-queries in a relational database.

\subsection{Measurement of network structure}

Quantification of the network structure was achieved by exploring i) network and ii) node properties, in order to investigate i) system-wide relationships (e.g., connectivity); and ii) the most highly connected host species involved in the cross-infestation with ticks and the transmission of tick-borne pathogens, respectively.

\subsubsection{Network properties: system-wide relationships}

The network property metrics (Table 1) provide information about host connectivity and frequency of interactions within the network (Salathé \& Jones 2010; MacIntosh et al. 2012). We measured the network's i) average degree, ii) density, iii) diameter, and iv) average path length (Proulx et al. 2005; Kiss et al. 2006; Jeger et al. 2007; Moore et al. 2014). The presence of sub-groups of hosts was depicted using v) the number of communities, vi) the network transitivity, and vii) the number of components (Newman \& Park 2003; Boccaletti et al. 2006; Moore et al. 2014). The properties of the observed networks were compared to 1000 random graphs generated using the Erdös-Renyi model (Erdös \& Rényi 1959). In every randomization, identical network metrics were calculated from randomly assembled graphs with the same number of vertices and edges as those in the observed networks. Each edge was considered to occur independently with the same probability of existing in the random graphs as the other edges.

\subsubsection{Node properties: most connected host species}

In order to identify host species having a key role in tick cross-infestation and potentially tick-borne disease transmission, we measured the node degree (May 2006) and betweenness score (Boccaletti et 
Table 1. Metrics used to measure network and node properties, their definition in terms of network structure and their interpretation in terms of tick-host interactions.

Network definition

Meaning for tick-host interactions and pathogen

circulation

\begin{tabular}{|c|c|c|}
\hline NETWORK PROPERTIES & & \\
\hline Average Degree & $\begin{array}{l}\text { Mean number of connections (edges) } \\
\text { per node }\end{array}$ & $\begin{array}{l}\text { Quantify the connectivity of hosts by ticks; a high } \\
\text { connectivity (indicated by a high average degree, } \\
\text { density or diameter or a low average path length) } \\
\text { should favour pathogen circulation }\end{array}$ \\
\hline Density & Ratio of edges to nodes & \\
\hline Average path length & $\begin{array}{l}\text { Mean shortest path among all nodes } \\
\text { on the network }\end{array}$ & \\
\hline Diameter & $\begin{array}{l}\text { Maximum shortest path between two } \\
\text { nodes }\end{array}$ & \\
\hline Number of communities & $\begin{array}{l}\text { Number of mammal species grouped } \\
\text { by dense attachment (connections) } \\
\text { internally }\end{array}$ & $\begin{array}{l}\text { Quantify the existence of sub-groups of hosts. Within } \\
\text { such groups disease circulation is favoured; between } \\
\text { groups, disease circulation is expected to be lower }\end{array}$ \\
\hline Transitivity & $\begin{array}{l}\text { Tendency of two nodes to be } \\
\text { connected when they share a } \\
\text { common neighbour }\end{array}$ & \\
\hline Number of components & $\begin{array}{l}\text { Presence of isolated groups of nodes } \\
\text { where the connection of nodes could } \\
\text { be interrupted }\end{array}$ & \\
\hline NODE PROPERTIES & & \\
\hline Degree & $\begin{array}{l}\text { Number of connections (edges) to } \\
\text { other nodes }\end{array}$ & $\begin{array}{l}\text { Measures the connectivity of each host to other hosts in } \\
\text { the network; a high connectivity favours pathogen } \\
\text { transmission to a large number of adjacent hosts }\end{array}$ \\
\hline Betweenness & $\begin{array}{l}\text { Number of shortest path going } \\
\text { through the node }\end{array}$ & $\begin{array}{l}\text { Measures the importance of a node as an intermediary } \\
\text { between different parts of the network (i.e., defines the } \\
\text { flow pathways); a high betweenness favours pathogen } \\
\text { circulation in the network }\end{array}$ \\
\hline
\end{tabular}


al. 2006) (Table 1). We considered a highly connected species to be any mammal species whose degree and/or betweenness value was one standard deviation away from the mean.

Since the underlying mechanisms of the transmission of tick-borne disease at an individual level are primarily based on transmission between tick stadia (Jongejan \& Uilenberg 2004; Socolovschi et al. 2009), inferences were made at the host community level. The likelihood of pathogen transmission was assumed to be positively correlated with increased network and node connectivity, represented in increased values of all network or node metrics and decreased values of average path length (Proulx et al. 2005; Kiss 2006; Moore et al. 2014).

\subsection{Influence of domestic hosts}

The influence of domestic mammals on network structure and the potential transmission of tick-borne pathogens was assessed by removing all domestic species from the three networks and comparing the resulting network metrics to those of networks in which the same number of species were randomly removed (hereafter 'simulated networks'). We removed eight domestic species from the network of mammals sharing all ticks, and seven from both the network of mammals sharing juvenile ticks and the network of mammals sharing adult ticks. The resulting networks were compared to 1000 simulated networks that were obtained by randomly removing eight or seven mammal species (wild or domestic), respectively. All network graphs were created using Gephi version 0.9.1 (Bastian et al. 2009) and network parameter calculations were carried out using the R package 'igraph 0.7.0.' (Csárd \& Nepusz 2006). 

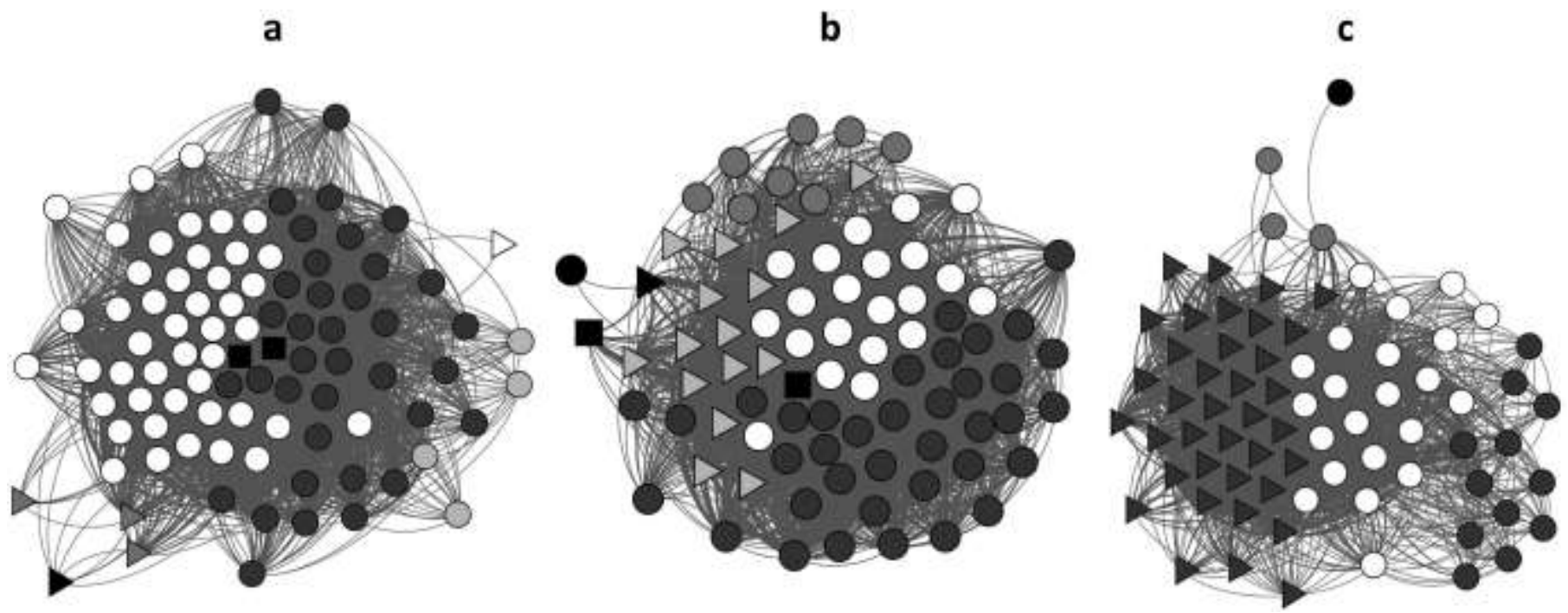

Figure 1. Networks of all mammal hosts connected by shared tick species when all tick life stages (a), juvenile ticks (b) and adult ticks (c) are considered. The different colours represent the different communities identified in each network. Communities size (number of host species): (a) white circles: 45, dark grey circles: 37, grey triangles: 3 , light grey circles: 4, black squares: 2 , white triangle: 1 , black triangle: 1; (b) grey circles: 8 , black squares: 2 , light grey triangles: 15 , dark grey circles: 37 , white circles: 21 , black triangle: 1 , black circle: 1 ; (c) grey circles: 3 , white circles: 22 , dark grey circles: 12, dark grey triangles: 37 , black circle: 1 .

\section{Results}

\subsection{Networks with all recorded mammal host species}

\subsubsection{Network of all hosts sharing all ticks}

When all tick life stages were considered, 93 host species were connected by a total of 3105 edges defined by 54 shared tick species. The network displayed seven communities in a single giant component with dense connections internally (Fig. 1a). Domestic species were present in two of the seven communities, which also had the largest number of species, i.e., 45 and 37 mammal species. The observed transitivity was higher and the average path length shorter?? lower than the simulated values. However, the observed network average degree, density, diameter and number of components were similar to that of the random graphs (Table 2). Node degree values ranged from 2 for the African bush elephant to 90 for the scrub hare and sheep. Node betweenness ranged from 0 (yellow mongoose, 
donkey, common genet, striped polecat, African bush elephant, round-eared elephant shrew, brown greater galago, western vlei rat, hamadryas baboon and bushveld gerbil) to 93.83 (scrub hare) (Supporting Information). Together with some wild hosts (e.g., scrub hare, lion, leopard, civet, blackbacked jackal, caracal, common eland), three domestic mammals (sheep, dog and goat) were identified as the most connected species based on their degree and betweenness values.

Table 2. Values of network properties exhibited by the Erdös-Renyi Graphs (mean value, CI: confidence interval), contrasted with parameter values for the observed mammal network for hosts that share all ticks, juvenile ticks and adult ticks.

\begin{tabular}{lllllll} 
NETWORK & \multicolumn{2}{l}{ ERDÖS-RENYI GRAPHS } & & \multicolumn{2}{l}{ OBSERVED NETWORKS } \\
PROPERTIES & All ticks & Juvenile ticks & Adult ticks & All & Juvenile & Adult \\
& & & & ticks & ticks & ticks \\
\hline Average degree* & 66.77 & 59.69 & 41.54 & 66.77 & 59.69 & 41.54 \\
Density* & 0.72 & 0.71 & 0.56 & 0.72 & 0.71 & 0.56 \\
Diameter* & 2 & 2 & 2 & 2 & 3 & 3 \\
Number of components* & 1 & 1 & 1 & 1 & 1 & 1 \\
Average path length & 1.28 & 1.3 & 1.45 & 1.27 & 1.29 & 1.459 \\
(CI) & $(1.2896-1.2897)$ & $(1.3058-1.3059)$ & $(1.4533-1.4535)$ & & \\
Transitivity & 0.71 & 0.69 & 0.54 & 0.84 & 0.85 & 0.76 \\
(CI) & $(0.7100-0.7102)$ & $(0.693-0.694)$ & $(0.5460-0.5464)$ & &
\end{tabular}

$*$ Standard deviation $=0$

\subsubsection{Network of all hosts sharing juvenile ticks}

When only juvenile ticks were considered, the network included 85 host mammal species (nodes) connected with a total of 2537 edges and 48 tick species. The network displayed seven communities in a single giant component with dense connections internally (Fig. 1b). Domestic species were present in three of the seven communities, some of which had the largest number of species, i.e., 8,37 and 21 
mammal species. The observed network diameter and transitivity were higher, and the average path length shorter ??? lower than the simulated values, while the observed values of network average degree, density and number of components were similar to that of the random graphs (Table 2). Node degree values ranged from 2 (round-eared elephant shrew) to 83 (scrub hare). Node betweenness ranged from 0 (southern African hedgehog, Cape porcupine, striped polecat, serval, round-eared elephant shrew, brown greater galago, western vlei rat and bushveld gerbil) to 121.19 (scrub hare) (Supporting Information). Together with some wild hosts (e.g., scrub hare, caracal, civet, lion, cheetah, impala, leopard, African wild dog, black-backed jackal), three domestic mammals were identified as the most connected nodes based on their high degree (dog and sheep) and betweenness (cat) values.

\subsubsection{Network of all mammal hosts sharing adult ticks}

When only adult ticks were considered, the network connected 75 host species (nodes) with a total of 1 558 edges and 51 tick species. The network displayed five communities in a single giant component with dense connections internally (Fig. 1c). Domestic species were present in two of the five communities, which also had the largest number of species, i.e., 22 and 37 mammal species. The observed network diameter, average path length and transitivity were higher than the simulated values, but the observed network average degree, density and number of components were similar to that of the random graphs (Table 2). Node degree values ranged from 1 for mice to 71 for dog. Node betweenness ranged from 0 (southern African hedgehog, yellow mongoose, donkey, slender mongoose, common genet, Cape genet, white-tailed mongoose, striped polecat, banded mongoose, klipspringer, bat-eared fox, mice, hamadryas baboon, South African springhare and four-striped grass mouse) to 116.10 (scrub hare) (Supporting Information). Together with some wild hosts (e.g., lion, leopard, cheetah, scrub hare, caracal, black-backed jackal, honey badger, eastern rock elephant shrew), four domestic mammals were 
identified as the most connected nodes based on their high degree (dog, sheep and goat) and betweenness (sheep, dog and cat) values.

\subsection{Networks excluding domestic mammal hosts}

\subsubsection{Network of wild hosts sharing all tick life stages}

From the initial dataset of mammalian hosts that shared ticks of all life stages, eight domestic species (cattle, dog, goat, donkey, horse, cat, sheep and black rat) were identified and removed. A network with 85 nodes (only wild hosts) sharing 52 tick species in 2526 edges was created. The network displayed eight communities in a single giant component (Fig. 2a). The observed average degree, density and transitivity values were lower, the observed average path length and diameter were higher, and the number of components was similar to those in the simulated networks (Table 3). Node degree values ranged from 2 (African bush elephant) to 82 (scrub hare). Node betweenness ranged from 0 (brown greater galago, western vlei rat, bushveld gerbil, striped polecat, round-eared elephant shrew, yellow mongoose, common genet, African bush elephant and hamadryas baboon) to 95.41 (scrub hare) (Supporting Information). The most connected wild hosts included the same species as in the network of mammals sharing all ticks, adding in five more based on their degree values (caracal, cheetah, common eland, spotted hyena and African wild dog), and two more (greater kudu and leopard) based on their betweenness values. 
a

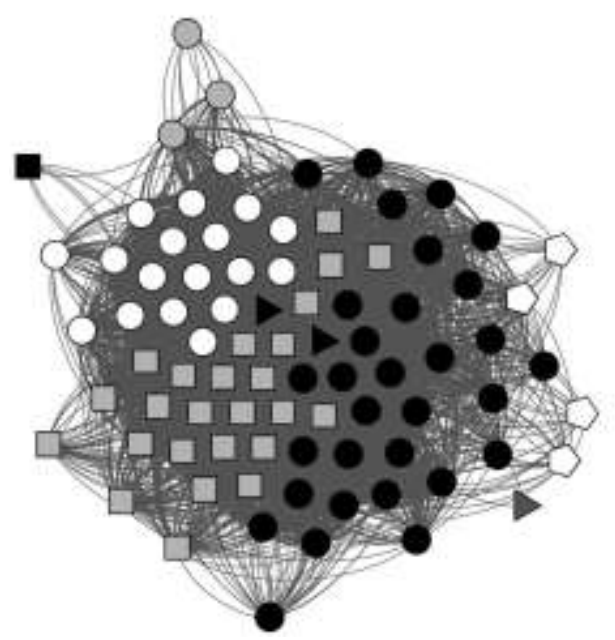

b

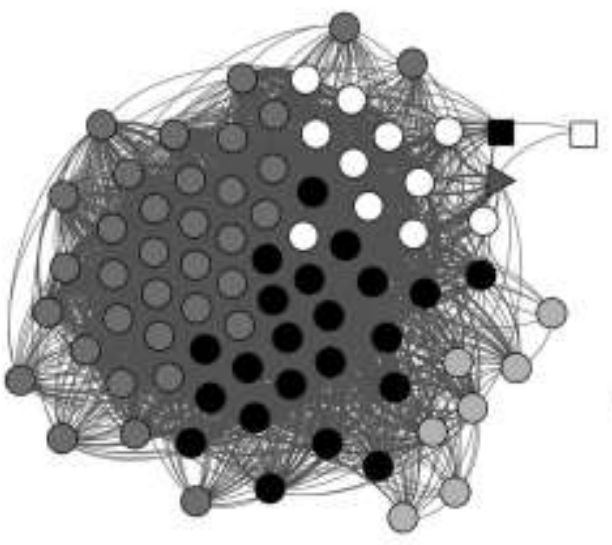

C

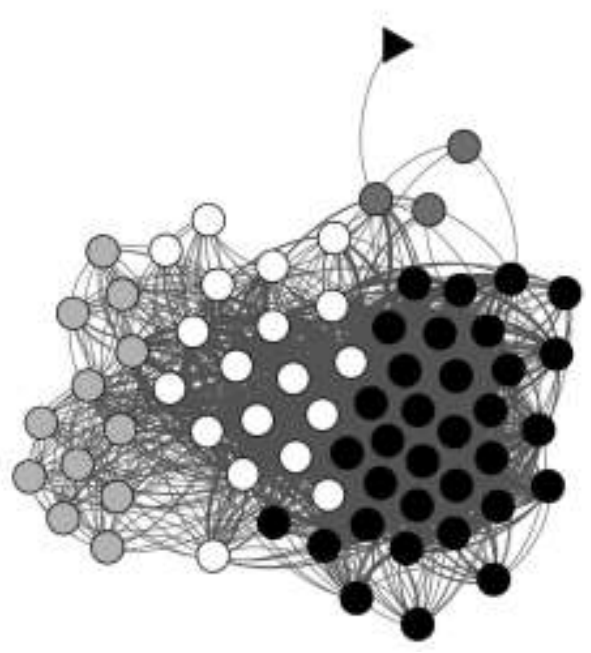

Figure 2. Networks of wild mammal hosts connected by shared tick species when all tick life stages (a), juvenile ticks (b) and adult ticks (c) are considered after domestic host species were removed. The different colours represent the different communities identified in each network. Communities size (number of host species): (a) light grey circles: 3, black circles: 31, white pentagons: 4 , white circles: 18 , light grey squares: 25 , black triangle: 2 , grey triangle: 1 , black square: 1 ; (b) light grey circles: 7 , grey circles: 35 , white circles: 11 , black circles: 22 , dark grey triangles: 1 , black square: 1 , white square: 1 ; (c) white circles: 19, grey circles: 3, light grey circles: 12, black circles: 33, black triangle: 1 . 
Table 3. Network properties of the observed networks excluding domestic species (mean value, CI: confidence interval), compared to 1000 simulated graphs obtained after having randomly removed the same number of host species.



\subsubsection{Networks of wild hosts sharing juvenile ticks}

From the initial dataset of mammalian hosts that shared juvenile ticks, seven domestic species (cattle, dog, goat, horse, cat, sheep and black rat) were identified and removed. A network of 78 nodes (only wild hosts) sharing 45 juvenile tick species in 2080 edges was created. The network displayed seven communities in a single giant component (Fig. 2b). The observed values of average degree, density and transitivity were lower, the observed average path length was higher, and diameter and the number of components were similar to those of the simulated networks (Table 3). The degree values of node properties ranged from 2 (round-eared elephant shrew) to 76 (scrub hare). Betweenness ranged from 0 (serval, brown greater galago, southern African hedgehog, Cape porcupine, western vlei rat, bushveld 
gerbil, striped polecat and round-eared elephant shrew) to 114.66 (scrub hare) (Supporting Information). The most connected wild hosts sharing juvenile ticks based on degree and betweenness values included the same species as in the network of all mammals, adding in one more for degree value (black-backed jackal).

\subsubsection{Network of wild hosts only sharing adult ticks}

From the initial dataset of mammalian hosts that shared adult ticks, seven domestic mammal species (cattle, dog, goat, donkey, horse, cat and sheep) were removed. A network of 68 nodes (only wild hosts) sharing adult ticks from 48 species in 1182 edges was created. The network displayed five communities in a single giant component (Fig. 2c). The observed values of average degree, density and transitivity were lower, the observed average path length and diameter were higher, and the number of components was similar to those of the simulated networks (Table 3). Node degree values ranged from 1 for mice to 62 for lion and leopard. Node betweenness ranged from 0 (klipspringer, southern African hedgehog, yellow mongoose, slender mongoose, common genet, Cape genet, banded mongoose, whitetailed mongoose, striped polecat, bat-eared fox, South African springhare, four-striped grass mouse, hamadryas baboon and mice) to 136.47 (scrub hare) (Supporting Information). Globally, except for network diameter, the differences between the observed (only wild hosts) and simulated (wild and domestic hosts) networks were more marked when considering adult ticks than when considering juvenile ticks. The most connected wild hosts sharing adult ticks included the same species as in the network of all mammals, adding in five more based on their degree values (African wild dog, spotted hyena, African civet, common eland and greater kudu), and three more (honey badger, African wild dog and spotted hyena) based on their betweenness values. 


\section{Discussion}

Our results showed that South African large and medium-sized mammal host species were highly connected by the tick species that they share, facilitating cross-infestation with ticks and the transmission of tick-borne pathogens. We also found that excluding domestic species from the networks significantly reduced overall network connectivity, indicating that domestic mammals may play a key role in facilitating the spread of ticks and tick-borne diseases in southern African mammal communities. These results indicate that conservation practices that mingle domestic livestock and wild mammals will lead to increased transmission of tick-borne pathogens in both domestic and wild populations.

The mean shortest pathway between any two mammal species and the tendency of some groups of mammals to be connected by the presence of others (transitivity) showed that there is a high probability for a potential pathogen to find a path to infect any other mammal species. The structure of the network thus facilitates pathogen spread (Godfrey 2013). This implies that after acquiring a pathogen during a blood meal, and off-host moulting, a tick would be able to choose between many mammal species to which it could spread a potential infection, particularly in the case of two- and three- host ticks.

Some highly connected mammal species appeared to contribute disproportionately to pathogen circulation among hosts. The scrub hare was the most connected (highest degree) and the most central (highest betweeness) in the network of mammals sharing ticks of any life stage and juvenile ticks, while the domestic dog was the most connected and the scrub hare the most central in the network of mammals sharing adult ticks. The eastern rock elephant shrew also appeared highly connected in some networks, but its high connectedness may be artefactual because large numbers (>800) of individuals were examined, but with only a low level of infestation. In constrast, the high connectedness of scrub hare is supported by the large number of individuals infested. Central hosts such as the scrub hare (i.e., 
hosts infested by many ticks that infest many other hosts in the network; Canright \& Engoe-Monsen 2006; Opsahl et al. 2010) may receive and transmit tick-borne diseases more frequently than noncentral species and therefore behave as 'super-spreaders' (Canright \& Engoe-Monsen 2006; Griffin \& Nunn 2012). Several tick species shared by the central highly connected mammal hosts, carry important pathogens that represent an animal and human health threat (Table 4). The identification of such host species is therefore crucial for developing surveillance protocols and interventions aimed at preventing future disease emergence.

Table 4. Some of the tick species shared by the most highly connected mammals identified in the networks (i.e., whose degree and/or betweenness value is at least one standard deviation away from the mean), pathogens they potentially transmit and diseases they produce.

\begin{tabular}{|c|c|c|c|}
\hline Tick species & $\begin{array}{l}\text { Highly connected host species (in } \\
\text { sequence of connectivity) ???? }\end{array}$ & $\begin{array}{l}\text { potentially transmitted by } \\
\text { that tick species }\end{array}$ & Disease \\
\hline Amblyomma hebraeum Koch, & cheetah, impala, cat, dog, jackal, & Ehrlichia ruminantium & Heartwater or \\
\hline \multirow{2}{*}{1844} & leopard, scrub hare, wild dog, eland, & & ruminants \\
\hline & honey badger, spotted hyena. & & \\
\hline \multirow[t]{3}{*}{ Hyalomma rufipes Koch, 1844} & goat, eastern rock elephant shrew, & Crimean-Congo & Crimean-Congo \\
\hline & scrub hare, sheep, eland. & haemorrhagic fever virus & haemorrhagic fever \\
\hline & & (Bunyaviridae: Nairovirus). & $(\mathrm{CCHF})$ \\
\hline Hyalomma truncatum Koch, & cheetah, impala, dog, goat, eastern & Crimean-Congo & Crimean-Congo \\
\hline 1844 & rock elephant shrew, scrub hare, & haemorrhagic fever virus & haemorrhagic fever \\
\hline
\end{tabular}




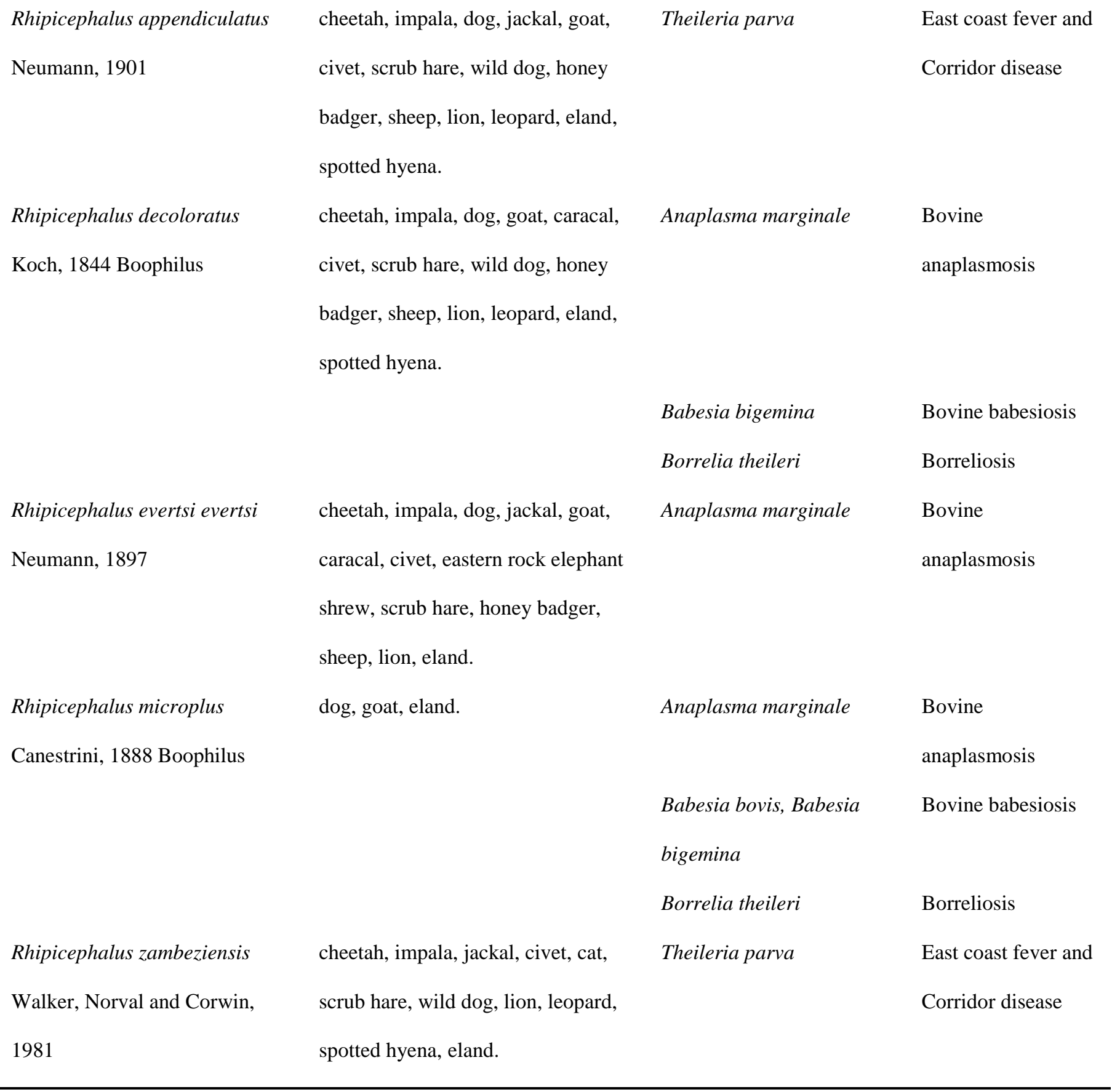

Our results indicate an important role played by domestic mammals in tick dynamics. Several domestic species (sheep, goat, dog and cat) were key nodes in the networks including all host species. (see Fig. 3 for a simplified network). Also, the exclusion of domestic species reduced the connectivity of the networks. The decrease in connectivity was more marked when considering adult ticks than juvenile ticks. This might indicate some preferences among adult ticks for domestic mammals, in 
accordance with a higher specificity of adult ticks previously observed in the same communities (Espinaze et al. 2016). Meanwhile, the high frequency of interactions induced by domestic mammals (in the simulated graphs) offered a greater number of potential routes for a disease to spread, thereby facilitating an interspecific transmission of pathogens. Our results thus support the hypothesis that although some South African ticks show some degree of specialization on wild animals, opportunistic feeding on domestic hosts can lead to shortened transmission pathways and the facilitation of pathogen spread between mammal species.

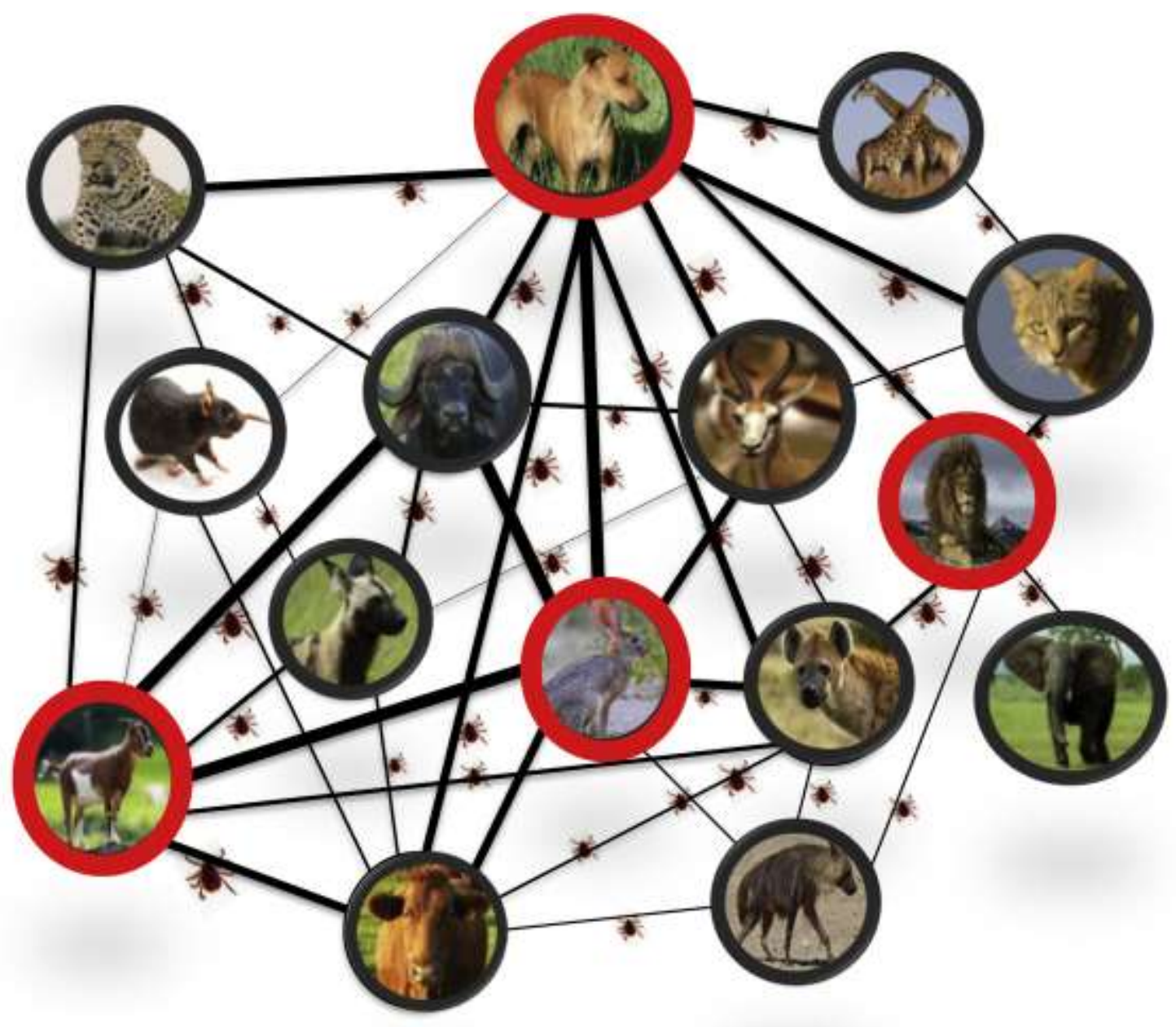

Fig. 3. Subset of a real-life network as a result of this study. Mammal species (wild or domestic) sharing tick species at all life stages are depicted. The thicker the line, the larger the number of tick species shared by the mammal species is. Some of the most-connected mammal species are highlighted with a red circle. 
Previous studies using ecological networks have also shown that a system with a large number of vertebrate species induces a cohesive network, and that domestic hosts modify the network structure increasing pathogen circulation and infection dynamics in the western Palearctic (Estrada-Peña et al. 2015). Mathematical analyses such as regression analysis and host community models have revealed that a high host species richness poses a high risk of cross-species parasite infestation. For instance, a higher richness of African bovid species facilitates gastrointestinal parasitism in an impala (Aepyceros melampus) population (Ezenwa 2004), and the diversity and identity of several vertebrate species are important factors influencing tick cross-infestation and tick-borne pathogen transmission (LoGiudice et al. 2008; Wells et al. 2013). Similarly, our results, do not support the hypothesis of a dilution effect (Schmidt \& Ostfeld 2001) due to an increased host diversity in mixed livestock-game systems .

Limiting contacts between wild and domestic mammals will decrease the risk of ticks and tickborne disease transmission. Adequate management measures to prevent disease spread in the wildlifedomestic animal interface are crucial, as pathogen spill-over from protected areas may have sociopolitical implications that represents a risk to wildlife conservation (Daszak et al. 2001; De Vos et al 2016). Small and isolated wild animal populations may be particularly vulnerable to disease, especially if they live in proximity to domestic animals (Daszak et al. 2001). Therefore, management actions should limit wildlife-domestic animal interactions. The use of fences around protected areas is one of the most common procedures to prevent the transmission of infectious diseases in South Africa (Jori et al. 2011; Hayward \& Somers 2012). Likewise, the identification and spatial separation of wildlife subgroups carrying pathogens (zoning) prevents disease spread into areas containing uninfected animals (Artois et al. 2011). The identification of the most connected wild host species and superspreaders allows surveillance systems to target them and more efficiently detect the emergence of possible diseases (Caron et al. 2012; Gortazar et al. 2015). Other management measures include the use of veterinary or medical control. However, it is acknowleged that the relationship between pathogens and 
their hosts is a natural element of functional ecosystems (Hudson et al. 2006; Tompkins et al. 2011; De Vos et al 2016), and so management using drugs such as acaricides is not suitable for wild populations. Alternatively, short-term vaccinations aimed at a specific wildlife population may reduce infection prevalence without the risk of drug resistance or harmful residues in the environment (Artois et al. 2011; Gortazar et al. 2015). Our results thus provide a clear indication that mixed systems of livestock and game are likely to prove more rather than less susceptible to tick-borne disease, with important implications for conservation management, particularly in the case of small wild populations and threatened and endangered species.

\section{Conclusions}

The transmission of ticks and tick-borne pathogens can potentially be facilitated among mammal species in South Africa. This is evidenced in the high connectivity exhibited by domestic and wild mammal species assessed through network analysis. Moreover, this study has uncovered the role played by domestic species in strengthening connectivity, and therefore their important contribution in the transmission of tick-borne pathogens among South African mammal species. This highlights the potential consequences of allowing contact between wild and domestic mammals, such as by sharing the same geographical area.

\section{Acknowledgements}

We thank René Navarro for assisting with the statistical analysis and Brent Abrahams for technical support in the network visualization. Capture of the tick data was supported by funding from the South African National Biodiversity Institute's SABIF (South African Biodiversity Information Facility) digitization program and the National Research Foundation of South Africa. 


\section{Literature cited}

Altizer S, Harvell D, Friedle E. 2003. Rapid evolutionary dynamics and disease threats to biodiversity. Trends in Ecology and Evolution 18:589-596.

Antia R, Regoes RR, Koella JC, Bergstrom CT. 2003. The role of evolution in the emergence of infectious diseases. Nature 426:658-661.

Artois M, Blancou J, Dupeyroux O, Gilot-Fromont E. 2011. Sustainable control of zoonotic pathogens in wildlife: how to be fair to wild animals?. Revue Scientifique et Technique-OIE 30: 733-743.

Bastian M, Heymann S, Jacomy M. 2009. Gephi: an open source software for exploring and manipulating networks. Proceedings of the Third International ICWSM Conference. International AAAI Conference on Weblogs and Media. San Jose, California.

Boccaletti S, Latora V, Moreno Y, Chavez M, Hwang DU. 2006. Complex networks: structure and dynamics. Physics Reports 424:175-308.

Canright GS, Engoe-Monsen K. 2006. Spreading on networks: A topographic view. Complexus 3:131-146.

Caron A, Morand S, de Garine-Wichatitsky M. 2012. Epidemiological interaction at the wildlife/livestock/human interface: can we anticipate emerging infectious diseases in their hotspots? A framework for understanding emerging diseases processes in their hot spots. Pages 311-332 in Morand S, Beaudeau F, Cabaret J, editors. New Frontiers of Molecular Epidemiology of Infectious Diseases. Springer, Netherlands.

Chomel BB, Belotto A, Meslin FX. 2007. Wildlife, exotic pets, and emerging zoonoses. Emerging Infectious Diseases 13:6-11.

Cleaveland S, Laurenson MK, Taylor LH. 2001. Diseases of humans and their domestic mammals: pathogen characteristics, host range and the risk of emergence. Philosophical Transactions of the Royal Society of London Series B 356:991-999.

Csárd G, Nepusz T. 2006. The igraph software package for complex network research. InterJournal, Complex Systems 1695:1-9.

Cumming GS. 1998. Host preference in African ticks (Acari: Ixodida): a quantitative data set. Bulletin of Entomological Research 88:379-406. 
Cumming GS. 1999. Host distributions do not limit the species ranges of most African ticks (Acari: Ixodida). Bulletin of Entomological Research 89:303-327.

Cumming GS, Van Vuuren DP. 2006. Will climate change affect ectoparasite species ranges?. Global Ecology and Biogeography 15:486-497.

Daszak P, Cunningham AA, Hyatt AD. 2000. Emerging infectious diseases of wildlife: threats to biodiversity and human health. Science 287:443-449.

Daszak P, Cunningham AA, Hyatt AD. 2001. Anthropogenic environmental change and the emergence of infectious diseases in wildlife. Acta Tropica 78:103-116.

De Vos A, Cumming GS, Cumming D, Ament JM, Baum J, Clements H, Grewar J, Maciejewski K and Moore C. 2016. Pathogens, disease, and the social-ecological resilience of protected areas. Ecology and Society 21:20.

Dobson A, Foufopoulos J. 2001. Emerging infectious pathogen in wildlife. Philosophical Transactions of the Royal Society of London Series B 356:1001-1012.

Espinaze MP, Hellard E, Horak IG, Cumming GS. 2016. Analysis of large new South African dataset using two host-specificity indices shows generalism in both adult and larval ticks of mammals. Parasitology 143:366.

Estrada-Peña A, de La Fuente J, Ostfeld RS, Cabezas-Cruz A. 2015. Interactions between tick and transmitted pathogens evolved to minimise competition through nested and coherent networks. Scientific reports 5:10361.

Erdős P, Rényi A. 1959. On random graphs I. Publicationes Mathematicae Debrecen 6:290-297.

Ezenwa VO. 2004. Parasite infection rates of impala (Aepyceros melampus) in fenced game reserves in relation to reserve characteristics. Biological Conservation 118:397-401.

Garamszegi LZ. 2011. Climate change increases the risk of malaria in birds. Global Change Biology 17:17511759.

Godfrey SS, Bull CM, James R, Murray K. 2009. Network structure and parasite transmission in a group living lizard, the gidgee skink, Egernia stokesii. Behavioral Ecology and Sociobiology 63:1045-1056.

Godfrey SS, Moore JA, Nelson NJ, Bull CM. 2010. Social network structure and parasite infection patterns in a territorial reptile, the tuatara (Sphenodon punctatus). International Journal for Parasitology 40:1575-1585. 
Godfrey SS. 2013. Networks and the ecology of parasite transmission: A framework for wildlife parasitology. International Journal for Parasitology: Parasites and Wildlife 2:235-245.

Gortazar C, Diez-Delgado I, Barasona JA, Vicente J, De La Fuente J, Boadella M. 2015. The wild side of disease control at the wildlife-livestock-human interface: a review. Frontiers in Veterinary Science 1:1-12.

Griffin RH, Nunn CL. 2012. Community structure and the spread of infectious disease in primate social networks. Evolutionary Ecology 26:779-800.

Han BA, Kramer AM, Drake JM. 2016. Global patterns of zoonotic disease in mammals. Trends in Parasitology 32:565-577.

Hassell JM, Begon M, Ward MJ, Fèvre EM. 2017. Urbanization and Disease Emergence: Dynamics at the Wildlife-Livestock-Human Interface. Trends in Ecology \& Evolution 32:55-67.

Hayward MW, Somers MJ. 2012. An introduction to fencing for conservation. Pages 1-6 in Somers MJ, Hayward MW, editors. Fencing for conservation. Springer, New York.

Hegglin D, Bontadina F, Deplazes P. 2015. Human-wildlife interactions and zoonotic transmission of Echinococcus multilocularis. Trends in Parasitology 31:167-173.

Hudson PJ, Dobson AP, Lafferty KD. 2006. Is a healthy ecosystem one that is rich in parasites?. Trends in Ecology \& Evolution 21:381-385.

Jeger MJ, Pautasso M, Holdenrieder O, Shaw MW. 2007. Modelling disease spread and control in networks: implications for plant sciences. New Phytologist 174:279-297.

Jongejan F, Uilenberg G. 2004. The global importance of ticks. Parasitology 129: S3-S14.

Jori F, Brahmbhatt D, Fosgate GT, Thompson PN, Budke C, Ward MP, Ferguson K, Gummow B. 2011. A questionnaire-based evaluation of the veterinary cordon fence separating wildlife and livestock along the boundary of the Kruger National Park, South Africa. Preventive Veterinary Medicine 100:210-220.

Karesh WB, Cook RA, Bennett EL, Newcomb J. 2005. Wildlife trade and global disease emergence. Emerging Infectious Diseases 11:1000-1002.

Keesing F, Holt RD, Ostfeld RS. 2006. Effects of species diversity on disease risk. Ecology Letters 9:485-498.

Kiss IZ, Green DM, Kao RR. 2006. The network of sheep movements within Great Britain: Network properties and their implications for infectious disease spread. Journal of the Royal Society Interface 3:669-677. 
LoGiudice K, Duerr ST, Newhouse MJ, Schmidt KA, Killilea ME, Ostfeld RS. 2008. Impact of host community composition on Lyme disease risk. Ecology 89:2841-2849.

Lubroth J. 2012. Climate change and animal health. Pages 63-69 in Meybeck A, Lankoski J, Redfern S, Azzu N, Gitz V, editors. Building resilience for the adaptation to climate change in the agriculture sector. Proceedings of a Joint FAO/OECD Workshop, Rome, Italy.

MacIntosh AJJ, Jacobs A, Garcia C, Shimizu K, Mouri K, Huffman MA, Hernandez AD. 2012. Monkeys in the Middle: Parasite Transmission through the Social Network of a Wild Primate. PLoS One 7:15-21.

May RM. 2006. Network structure and the biology of populations. Trends in Ecology and Evolution 21: 394 399.

Moore C, Cumming GS, Slingsby J, Grewar J. 2014. Tracking socioeconomic vulnerability using network analysis: Insights from an avian influenza outbreak in an ostrich production network. PLoS One 9:1-12.

Newman MEJ, Park J. 2003. Why social networks are different from other types of networks. Physical Review E 68:036122.

Olesen JM, Bascompte J, Elberling H, Jordano P. 2008. Temporal dynamics in a pollination network. Ecology 89:1573-1582.

Opsahl T, Agneessens F, Skvoretz J. 2010. Node centrality in weighted networks: generalizing degree and shortest paths. Social Networks 32:245-251.

Pastoret PP, Thiry E, Brochier B, Schwers A, Thomas I, Dubuisson J. 1988. Diseases of wild animals transmissible to domestic animals. Revue Scientifique et Technique de l'OIE 7:705-736.

Patz JA, et al. 2004. Unhealthy landscapes: policy recommendations on land use change and infectious disease emergence. Environmental Health Perspectives 112:1092-1098

Penzhorn BL. 2006. Babesiosis of wild carnivores and ungulates. Veterinary Parasitology 138:11-21.

Pilosof S, Morand S, Krasnov BR, Nunn CL. 2015. Potential parasite transmission in multi-host networks based on parasite sharing. PLoS One 10:e0117909.

Poulin R. 2010. Network analysis shining light on parasite ecology and diversity. Trends in Parasitology 26:492-498.

Power AG, Mitchell CE. 2004. Pathogen spillover in disease epidemics. The American Naturalist 164:S79-S89. 
Prager KC, et al. 2012a. The effect of protected areas on pathogen exposure in endangered African wild dog (Lycaon pictus) populations. Biological Conservation 150:15-22.

Prager KC, Mazet JAK, Dubovi EJ, Frank LG, Munson L, Wagner AP, Woodroffe R. 2012b. Rabies Virus and Canine Distemper Virus in Wild and Domestic Carnivores in Northern Kenya: Are Domestic Dogs the Reservoir? EcoHealth 9:483-498.

Proulx SR, Promislow DEL, Phillips PC. 2005. Network thinking in ecology and evolution. Trends in Ecology and Evolution 20:345-353.

Roelke-Parker ME, Munson L, Packer C, Kock R. 1996. A canine distemper virus epidemic in Serengeti lions (Panthera leo). Nature 379:441-445.

Salathé M, Jones JH. 2010. Dynamics and control of diseases in networks with community structure. PLoS Computational Biology 6:e1000736.

Schmidt KA, Ostfeld RS. 2001. Biodiversity and the dilution effect in disease ecology. Ecology 82:609-619.

Socolovschi C, Huynh TP, Davoust B, Gomez J, Raoult D, Parola P. 2009. Transovarial and trans-stadial transmission of Rickettsiae africae in Amblyomma variegatum ticks. European Society of Clinical Microbiology and Infectious Diseases 15:317-318.

Taylor RD, Martin RB. 1987. Effects of veterinary fences on wildlife conservation in Zimbabwe. Environmental Management 11:327-334.

Tompkins DM, Dunn AM, Smith MJ, Telfer S. 2011. Wildlife diseases: from individuals to ecosystems. Journal of Animal Ecology 80:19-38.

Wells K, O’Hara RB, Pfeiffer M, Lakim MB, Petney TN, Durden LA. 2013. Inferring host specificity and network formation through agent-based models: tick-mammal interactions in Borneo. Oecologia 172:307316.

Woolhouse MEJ, Taylor LH, Haydon DT. 2001. Population Biology of Multihost Pathogens. Science 292:1109_ 1112. 


\section{Supporting Information}

Appendix A. The 54 tick species considered in the network analysis, their scientific names, number of collections and number of mammal host species on which ticks were found. Collections refer to whenever a tick species is sampled from a host (i.e., there can be many ticks of a given species collected in a sample from a host).

\begin{tabular}{|c|c|c|}
\hline Tick species scientific name & $\begin{array}{l}\text { Number of } \\
\text { collections }\end{array}$ & $\begin{array}{c}\text { Number of host } \\
\text { species }\end{array}$ \\
\hline Amblyomma nuttalli Dönitz, 1909 & 2 & 2 \\
\hline Rhipicephalus lunulatus Neumann, 1907 & 2 & 2 \\
\hline Rhipicephalus theileri Bedford and Hewitt, 1925 & 2 & 2 \\
\hline Ixodes rhabdomysae Arthur, 1959 & 3 & 2 \\
\hline Rhipicephalus evertsi mimeticus Dönitz, 1910 & 3 & 2 \\
\hline Rhipicephalus simpsoni Nuttall, 1910 & 3 & 3 \\
\hline Rhipicephalus sulcatus Neumann, 1908 & 3 & 2 \\
\hline Amblyomma tholloni Neumann, 1899 & 4 & 3 \\
\hline Ixodes alluaudi Neumann, 1913 & 4 & 2 \\
\hline Rhipicephalus tricuspis Dönitz, 1906 & 5 & 2 \\
\hline Ixodes bakeri Arthur and Clifford, 1961 & 8 & 4 \\
\hline Ixodes cavipalpus Nuttall and Warburton, 1908 & 8 & 2 \\
\hline Rhipicephalus neumanni Walker, 1990 & 11 & 5 \\
\hline Ixodes corwini Keirans, Clifford and Walker, 1982 & 12 & 2 \\
\hline Dermacentor rhinocerinus Denny, 1843 & 15 & 5 \\
\hline Rhipicephalus zumpti Santos Dias, 1950 & 15 & 2 \\
\hline Haemaphysalis colesbergensis Apanaskevich and Horak, 2008 & 27 & 2 \\
\hline Haemaphysalis aciculifer Warburton, 1913 & 34 & 8 \\
\hline Rhipicephalus lounsburyi Walker, 1990 & 45 & 10 \\
\hline Rhipicephalus capensis Koch, 1844 & 47 & 12 \\
\hline Haemaphysalis parmata Neumann, 1905 & 91 & 4 \\
\hline Haemaphysalis hyracophila Hoogstraal, Walker and Neitz, 1971 & 100 & 3 \\
\hline Hyalomma glabrum Delpy, 1949 & 104 & 10 \\
\hline Haemaphysalis zumpti Hoogstraal and El Kammah, 1974 & 114 & 23 \\
\hline Rhipicephalus kochi Dönitz, 1905 & 118 & 7 \\
\hline Rhipicephalus turanicus Pomerantzev, 1940 & 124 & 12 \\
\hline Rhipicentor nuttalli Cooper and Robinson, 1908 & 145 & 5 \\
\hline Rhipicephalus exophthalmos Keirans and Walker, 1993 & 152 & 11 \\
\hline Margaropus winthemi Karsch, 1879 & 160 & 14 \\
\hline Haemaphysalis spinulosa Neumann, 1906 & 165 & 21 \\
\hline Rhipicephalus maculatus Neumann, 1901 & 203 & 9 \\
\hline Rhipicephalus oculatus Neumann, 1901 & 300 & 7 \\
\hline Rhipicephalus arnoldi Theiler and Zumpt, 1949 & 392 & 8 \\
\hline Rhipicephalus muehlensi Zumpt, 1943 & 398 & 10 \\
\hline Rhipicephalus nitens Neumann, 1904 & 514 & 6 \\
\hline Rhipicephalus gertrudae Feldman-Muhsam, 1960 & 526 & 30 \\
\hline
\end{tabular}


Rhipicephalus follis Dönitz, 1910

Rhipicephalus distinctus Bedford, 1932

Ixodes pilosus Koch, 1844

562

Hyalomma rufipes Koch, 1844

616

Rhipicephalus microplus Canestrini, 1888 Boophilus

799

Amblyomma marmoreum Koch, 1844

894

Haemaphysalis silacea Robinson, 1912

936

Rhipicephalus warburtoni Walker and Horak, 2000

950

Rhipicephalus zambeziensis Walker, Norval and Corwin, 1981

1052

Ixodes rubicundus Neumann, 1904

1104

Rhipicephalus simus Koch, 1844

1242

42

Rhipicephalus glabroscutatus Du Toit, 1941

1509

Hyalomma truncatum Koch, 1844

1608

Haemaphysalis elliptica Koch, 1844

1954

36

Rhipicephalus decoloratus Koch, 1844 _Boophilus

3177

42

Rhipicephalus appendiculatus Neumann, 1901

3380

Amblyomma hebraeum Koch, 1844

4236

48

Rhipicephalus evertsi evertsi Neumann, 1897

6393

45

Appendix B. Mammal host species, their scientific names, common names and type of animal (wild or domestic).

\begin{tabular}{lll}
\hline Mammal species scientific name & Mammal species common name & Type \\
\hline Otolemur crassicaudatus & Brown greater galago & wild \\
Papio hamadryas & Hamadryas baboon & wild \\
Loxodonta africana & African bush elephant & wild \\
Macroscelides proboscideus & Round-eared elephant shrew & wild \\
Otomys occidentalis & Western Vlei Rat & wild \\
Genetta genetta & Common genet & wild \\
Ictonyx striatus & Striped polecat & wild \\
Soricidae & Shrew & wild \\
Rhynchogale melleri & Meller's mongoose & wild \\
Oreotragus oreotragus & Klipspringer & wild \\
Parahyaena brunnea & Brown hyena & wild \\
Cynictis penicillata & Yellow mongoose & wild \\
Tatera leucogaster & Bushveld gerbil & wild \\
Mastomys natalensis & Natal multimammate mouse & wild \\
Saccostomus campestris & South African pouched mouse & wild \\
Hystrix africaeaustralis & Cape porcupine & wild \\
Praomys sp. & Rodent & wild \\
Hippotragus niger & Sable antelope & wild \\
Elephantulus brachyrhynchus & Short-snouted elephant shrew & wild \\
Otocyon megalotis & Bat-eared fox & wild \\
\hline
\end{tabular}




\begin{tabular}{|c|c|c|}
\hline Suricata suricatta & Meerkat & wild \\
\hline Leptailurus serval & Serval & wild \\
\hline Chlorocebus aethiops & Grivet & wild \\
\hline Mastomys coucha & Southern multimammate mouse & wild \\
\hline Galerella sanguinea & Slender mongoose & wild \\
\hline Vulpes chama & Cape fox & wild \\
\hline Ichneumia albicauda & White-tailed mongoose & wild \\
\hline Mungos mungo & Banded mongoose & wild \\
\hline Aethomys namaquensis & Namaqua rock rat & wild \\
\hline Felis nigripes & Black-footed cat & wild \\
\hline Galerella pulverulenta & Cape gray mongoose & wild \\
\hline Proteles cristatus & Aardwolf & wild \\
\hline Felis silvestris & Wildcat & wild \\
\hline Genetta sp. & Genets & wild \\
\hline Lemniscomys rosalia & Single-striped grass mouse & wild \\
\hline Atelerix frontalis & Southern African hedgehog & wild \\
\hline Hippotragus equinus & Roan antelope & wild \\
\hline Raphicerus campestris & Steenbok & wild \\
\hline Neotragus moschatus & Suni & wild \\
\hline Alcelaphus buselaphus & Hartebeest & wild \\
\hline Genetta tigrina & Cape genet & wild \\
\hline Mellivora capensis & Honey badger & wild \\
\hline Pedetes capensis & South African springhare & wild \\
\hline Damaliscus lunatus & Common tsessebe & wild \\
\hline Crocuta crocuta & Spotted hyena & wild \\
\hline Aethomys chrysophilus & Red rock rat & wild \\
\hline Potamochoerus larvatus & Bushpig & wild \\
\hline Otomys sp. & Mice & wild \\
\hline Acinonyx jubatus & Cheetah & wild \\
\hline Raphicerus melanotis & Cape grysbok & wild \\
\hline Ceratotherium simum & White rhinoceros & wild \\
\hline Antidorcas marsupialis & Springbok & wild \\
\hline Canis mesomelas & Black-backed jackal & wild \\
\hline Elephantulus edwardii & Cape elephant shrew & wild \\
\hline Rhabdomys pumilio & Four-striped grass mouse & wild \\
\hline Panthera pardus & Leopard & wild \\
\hline Lycaon pictus & African wild dog & wild \\
\hline Diceros bicornis & Black rhinoceros & wild \\
\hline Civettictis civetta & African civet & wild \\
\hline Oryx gazella & Gemsbok & wild \\
\hline Sylvicapra grimmia & Common duiker & wild \\
\hline Connochaetes gnou & Black wildebeest & wild \\
\hline Giraffa camelopardalis & Giraffe & wild \\
\hline
\end{tabular}




\begin{tabular}{lll}
\hline Redunca fulvorufula & Mountain reedbuck & wild \\
Cephalophus natalensis & Red forest duiker & wild \\
Redunca arundinum & Southern reedbuck & wild \\
Pronolagus rupestris & Smith's red rock hare & wild \\
Tragelaphus scriptus & Bushbuck & wild \\
Equus zebra & Mountain zebra & wild \\
Lepus capensis & Cape hare & wild \\
Panthera leo & Lion & wild \\
Caracal caracal & Caracal & wild \\
Damaliscus pygargus & Bontebok & wild \\
Pelea capreolus & Grey rhebok & wild \\
Taurotragus oryx & Common eland & wild \\
Connochaetes taurinus & Blue wildebeest & wild \\
Syncerus caffer & African buffalo & wild \\
Equus burchelli & Plains zebra & wild \\
Phacochoerus africanus & Warthog & wild \\
Elephantulus myurus & Eastern rock elephant shrew & wild \\
Procavia capensis & Rock hyrax & wild \\
Tragelaphus angasii & Nyala & wild \\
Tragelaphus strepsiceros & Greater kudu & wild \\
Aepyceros melampus & Impala & wild \\
Lepus saxatilis & Scrub hare & wild \\
Ovis aries & Sheep & domestic \\
Equus asinus & Donkey & domestic \\
Capra hircus & Goat & domestic \\
Canis lupus familiaris & Dog & domestic \\
Equus caballus & Horse & domestic \\
Felis catus & Cat & domestic \\
Bos sp. Bos taurus/indicus) & Cattle & domestic \\
\hline & Black rat & domestic \\
\hline
\end{tabular}

Appendix C. Node property values (degree and betweenness) of mammal hosts sharing all ticks. The most connected species in bold.

\begin{tabular}{lll}
\hline Mammal species sharing all ticks & Degree & Betweenness \\
\hline Lepus saxatilis & $\mathbf{9 0}$ & $\mathbf{9 3 . 8 3}$ \\
Ovis aries & $\mathbf{9 0}$ & $\mathbf{4 4 . 5 0}$ \\
Canis lupus familiaris & $\mathbf{8 9}$ & $\mathbf{3 2 . 6 6}$ \\
Panthera leo & $\mathbf{8 8}$ & $\mathbf{7 0 . 7 4}$ \\
Capra hircus & $\mathbf{8 7}$ & $\mathbf{2 9 . 4 6}$ \\
Canis mesomelas & $\mathbf{8 7}$ & $\mathbf{2 9 . 1 1}$ \\
Civettictis civetta & $\mathbf{8 7}$ & $\mathbf{2 8 . 5 2}$ \\
Panthera pardus & $\mathbf{8 7}$ & 26.74 \\
Taurotragus oryx & 86 & $\mathbf{2 7 . 9 5}$ \\
Bos sp. & 86 & 25.98
\end{tabular}




\begin{tabular}{|c|c|c|}
\hline Crocuta crocuta & 86 & 24.78 \\
\hline Lycaon pictus & 86 & 24.78 \\
\hline Acinonyx jubatus & 86 & 22.66 \\
\hline Caracal caracal & 85 & 31.69 \\
\hline Felis catus & 84 & 23.30 \\
\hline Tragelaphus strepsiceros & 84 & 23.24 \\
\hline Mellivora capensis & 84 & 20.44 \\
\hline Aepyceros melampus & 84 & 15.06 \\
\hline Genetta sp. & 83 & 19.16 \\
\hline Damaliscus pygargus & 83 & 16.13 \\
\hline Syncerus caffer & 83 & 14.68 \\
\hline Phacochoerus africanus & 83 & 14.47 \\
\hline Felis silvestris & 82 & 23.02 \\
\hline Giraffa camelopardalis & 82 & 13.56 \\
\hline Mungos mungo & 81 & 17.26 \\
\hline Proteles cristatus & 81 & 14.30 \\
\hline Tragelaphus scriptus & 80 & 12.83 \\
\hline Rhabdomys pumilio & 79 & 23.36 \\
\hline Equus caballus & 79 & 13.31 \\
\hline Ceratotherium simum & 79 & 11.46 \\
\hline Equus burchelli & 78 & 10.29 \\
\hline Cephalophus natalensis & 78 & 8.79 \\
\hline Elephantulus myurus & 77 & 20.24 \\
\hline Hippotragus equinus & 77 & 9.48 \\
\hline Aethomys chrysophilus & 76 & 10.25 \\
\hline Ichneumia albicauda & 75 & 10.64 \\
\hline Connochaetes gnou & 74 & 9.18 \\
\hline Otomys sp. & 74 & 8.51 \\
\hline Redunca arundinum & 74 & 6.66 \\
\hline Tragelaphus angasii & 74 & 6.39 \\
\hline Chlorocebus aethiops & 73 & 7.72 \\
\hline Neotragus moschatus & 73 & 6.06 \\
\hline Genetta tigrina & 72 & 10.70 \\
\hline Diceros bicornis & 72 & 7.04 \\
\hline Connochaetes taurinus & 72 & 5.91 \\
\hline Raphicerus campestris & 72 & 5.91 \\
\hline Lepus capensis & 71 & 7.67 \\
\hline Hystrix africaeaustralis & 71 & 6.94 \\
\hline Equus zebra & 71 & 5.84 \\
\hline Potamochoerus larvatus & 70 & 6.67 \\
\hline Damaliscus lunatus & 70 & 4.91 \\
\hline Sylvicapra grimmia & 70 & 4.91 \\
\hline Pedetes capensis & 69 & 16.31 \\
\hline Procavia capensis & 69 & 13.61 \\
\hline Pronolagus rupestris & 69 & 13.61 \\
\hline Antidorcas marsupialis & 69 & 12.66 \\
\hline Pelea capreolus & 69 & 10.88 \\
\hline Leptailurus serval & 69 & 9.11 \\
\hline
\end{tabular}


Oryx gazella

Redunca fulvorufula

Otocyon megalotis

Praomys sp.

Oreotragus oreotragus

Galerella pulverulenta

Vulpes chama

Mastomys natalensis

Alcelaphus buselaphus

Suricata suricatta

Aethomys namaquensis

Lemniscomys rosalia

Mastomys coucha

Hippotragus niger

Raphicerus melanotis

Parahyaena brunnea

Galerella sanguinea

Atelerix frontalis

Rhynchogale melleri

Felis nigripes

Otolemur crassicaudatus

Rattus rattus

Soricidae

Equus asinus

Otomys occidentalis

Tatera leucogaster

Elephantulus edwardii

Elephantulus brachyrhynchus

Saccostomus campestris

Cynictis penicillata

Genetta genetta

Ictonyx striatus

Macroscelides proboscideus

Papio hamadryas

Loxodonta africana
69

66

64

64

64

63

63

63

62

61

61

61

61

60

60

54

53

52

50

48

47

46

44

43

41

41

40

39

25

22

22

20

10

10
6.65

10.84

6.40

4.52

2.04

21.39

11.35

3.92

2.56

9.26

4.39

4.39

4.39

2.55

1.91

1.96

5.28

4.32

1.86

5.92

0

1.33

0.18

0

0

0

8.08

0.03

1.61

0

0

0

0

Appendix D. Node property values (degree and betweenness) of mammal hosts sharing juvenile ticks. The most connected species in bold.

\begin{tabular}{lll}
\hline Mammal species sharing juvenile ticks & Degree & Betweenness \\
\hline Lepus saxatilis & $\mathbf{8 3}$ & $\mathbf{1 2 1 . 1 9}$ \\
Caracal caracal & $\mathbf{8 1}$ & $\mathbf{5 0 . 9 7}$ \\
Civettictis civetta & $\mathbf{8 1}$ & $\mathbf{4 3 . 8 3}$ \\
Acinonyx jubatus & $\mathbf{8 0}$ & $\mathbf{3 0 . 4 9}$ \\
Aepyceros melampus & $\mathbf{8 0}$ & $\mathbf{3 0 . 4 9}$ \\
Panthera leo & $\mathbf{8 0}$ & $\mathbf{3 0 . 4 9}$ \\
Canis lupus familiaris & $\mathbf{7 9}$ & 24.39 \\
Lycaon pictus & $\mathbf{7 9}$ & 24.39 \\
& & 33
\end{tabular}


Ovis aries

Panthera pardus

Felis catus

Canis mesomelas

Capra hircus

Genetta sp.

Mungos mungo

Felis silvestris

Tragelaphus scriptus

Crocuta crocuta

Cephalophus natalensis

Proteles cristatus

Giraffa camelopardalis

Phacochoerus africanus

Taurotragus oryx

Tragelaphus angasii

Tragelaphus strepsiceros

Ichneumia albicauda

Bos sp.

Redunca arundinum

Syncerus caffer

Elephantulus myurus

Rhabdomys pumilio

Neotragus moschatus

Connochaetes taurinus

Equus burchelli

Raphicerus campestris

Damaliscus pygargus

Genetta tigrina

Damaliscus lunatus

Hippotragus equinus

Mellivora capensis

Sylvicapra grimmia

Otomys sp.

Chlorocebus aethiops

Lepus capensis

Procavia capensis

Pronolagus rupestris

Pedetes capensis

Oreotragus oreotragus

Aethomys chrysophilus

Praomys sp.

Pelea capreolus
79

79

78

78

78

76

75

74

74

73

73

72

72

72

72

72

72

71

71

71

71

70

69

68

68

68

68

67

67

67

67

67

67

66

66

65

64

64

63

63

61

61

61
24.39

24.39

33.18

31.86

24.92

19.74

18.50

14.95

14.86

20.35

14.19

22.23

12.89

8.77

8.77

8.77

8.77

12.51

7.81

7.81

7.81

23.31

28.03

6.66

6.07

6.07

6.07

9.66

5.73

5.21

5.21

5.21

5.21

14.89

10.64

14.18

15.16

15.16

19.62

3.22

18.03

8.35

2.61 


\begin{tabular}{lll} 
Antidorcas marsupialis & 60 & 8.70 \\
Connochaetes gnou & 60 & 8.70 \\
Redunca fulvorufula & 60 & 8.70 \\
Otocyon megalotis & 59 & 14.11 \\
Alcelaphus buselaphus & 59 & 2.93 \\
Raphicerus melanotis & 59 & 2.57 \\
Mastomys natalensis & 58 & 8.60 \\
Equus caballus & 58 & 1.38 \\
Equus zebra & 58 & 1.38 \\
Oryx gazella & 58 & 1.38 \\
Ceratotherium simum & 52 & 1.09 \\
Suricata suricatta & 52 & 0.69 \\
Galerella pulverulenta & 51 & 7.29 \\
Potamochoerus larvatus & 51 & 0.56 \\
Diceros bicornis & 49 & 0.17 \\
Leptailurus serval & 47 & 0 \\
Otolemur crassicaudatus & 47 & 0 \\
Atelerix frontalis & 45 & 0 \\
Hystrix africaeaustralis & 45 & 0 \\
Rhynchogale melleri & 44 & 3.02 \\
Galerella sanguinea & 43 & 0.40 \\
Mastomys coucha & 39 & 4.14 \\
Soricidae & 39 & 0.16 \\
Aethomys namaquensis & 37 & 4.14 \\
Lemniscomys rosalia & 37 & 4.14 \\
Vulpes chama & 32 & 3.49 \\
Rattus rattus & 32 & 0.72 \\
Otomys occidentalis & 22 & 0 \\
Tatera leucogaster & 22 & 0 \\
Elephantulus edwardii & 18 & 9.44 \\
Saccostomus campestris & 14 & 0.12 \\
Elephantulus brachyrhynchus & 14 & 0.02 \\
Ictonyx striatus & 8 & 0 \\
Macroscelides proboscideus & 2 & 0 \\
\hline & & \\
& &
\end{tabular}

Appendix E. Node property values (degree and betweenness) of mammal hosts sharing adult ticks. The most connected species in bold.

\begin{tabular}{lll}
\hline Mammal species sharing adult ticks & Degree & Betweenness \\
\hline Canis lupus familiaris & $\mathbf{7 1}$ & $\mathbf{8 2 . 5 3}$ \\
Ovis aries & $\mathbf{7 0}$ & $\mathbf{9 7 . 3 6}$ \\
Panthera pardus & 69 & $\mathbf{7 3 . 2 2}$ \\
Panthera leo & 69 & $\mathbf{6 5 . 4 9}$ \\
Lepus saxatilis & 67 & $\mathbf{1 1 6 . 1 0}$
\end{tabular}


Acinonyx jubatus

Mellivora capensis

Caracal caracal

Capra hircus

Canis mesomelas

Lycaon pictus

Crocuta crocuta

Bos sp.

Felis catus

Civettictis civetta

Taurotragus oryx

Tragelaphus strepsiceros

Giraffa camelopardalis

Damaliscus pygargus

Phacochoerus africanus

Syncerus caffer

Equus burchelli

Hippotragus equinus

Tragelaphus angasii

Equus caballus

Aepyceros melampus

Ceratotherium simum

Connochaetes taurinus

Vulpes chama

Leptailurus serval

Connochaetes gnou

Tragelaphus scriptus

Damaliscus lunatus

Redunca arundinum

Diceros bicornis

Felis silvestris

Equus zebra

Potamochoerus larvatus

Oryx gazella

Genetta sp.

Antidorcas marsupialis

Raphicerus campestris

Redunca fulvorufula

Pelea capreolus

Hippotragus niger

Proteles cristatus

Hystrix africaeaustralis

Parahyaena brunnea
65

63

61

60

59

58

58

58

57

57

57

57

55

54

53

53

52

52

50

50

50

50

49

48

47

47

47

47

47

46

45

45

45

44

43

43

43

42

42

39

38

38

37
49.13

41.74

42.51

29.87

47.07

40.38

38.09

20.84

43.55

37.38

20.54

20.54

16.78

15.87

8.94

8.94

8.15

8.15

8.26

7.32

6.72

5.98

5.94

24.66

14.62

10.96

6.30

5.03

5.03

4.04

28.01

17.60

4.16

4.11

15.75

3.34

2.81

7.54

3.83

1.55

6.81

1.41

6.70 


\begin{tabular}{lll} 
Procavia capensis & 36 & 19.80 \\
Felis nigripes & 35 & 8.88 \\
Sylvicapra grimmia & 35 & 0.87 \\
Alcelaphus buselaphus & 35 & 0.32 \\
Cephalophus natalensis & 32 & 8.12 \\
Galerella pulverulenta & 29 & 3.59 \\
Suricata suricatta & 29 & 3.59 \\
Equus asinus & 29 & 0 \\
Oreotragus oreotragus & 29 & 0 \\
Neotragus moschatus & 28 & 0.23 \\
Atelerix frontalis & 22 & 0 \\
Cynictis penicillata & 22 & 0 \\
Galerella sanguinea & 22 & 0 \\
Genetta genetta & 22 & 0 \\
Genetta tigrina & 22 & 0 \\
Mungos mungo & 22 & 0 \\
Elephantulus myurus & 21 & $\mathbf{8 4 . 3 1}$ \\
Lepus capensis & 21 & 4.29 \\
Raphicerus melanotis & 20 & 0.06 \\
Ichneumia albicauda & 20 & 0 \\
Ictonyx striatus & 20 & 0 \\
Otocyon megalotis & 20 & 0 \\
Pedetes capensis & 19 & 0 \\
Rhabdomys pumilio & 19 & 0 \\
Pronolagus rupestris & 6 & 0.30 \\
Papio hamadryas & 3 & 0 \\
Otomys sp. & 1 & 0 \\
\hline & & \\
& &
\end{tabular}

Appendix F. Node property values (degree and betweenness) of wild mammals sharing all ticks. The most connected species in bold.

\begin{tabular}{lll}
\hline Wild mammal species sharing all ticks & Degree & Betweenness \\
\hline Lepus saxatilis & $\mathbf{8 2}$ & $\mathbf{9 5 . 4 1}$ \\
Panthera leo & $\mathbf{8 0}$ & $\mathbf{6 8 . 0 5}$ \\
Canis mesomelas & $\mathbf{7 9}$ & $\mathbf{3 1 . 2 9}$ \\
Civettictis civetta & $\mathbf{7 9}$ & $\mathbf{3 0 . 2 7}$ \\
Panthera pardus & $\mathbf{7 9}$ & $\mathbf{2 8 . 0 5}$ \\
Caracal caracal & $\mathbf{7 8}$ & $\mathbf{3 3 . 2 2}$ \\
Taurotragus oryx & $\mathbf{7 8}$ & $\mathbf{3 3 . 2 0}$ \\
Crocuta crocuta & $\mathbf{7 8}$ & 25.69 \\
Lycaon pictus & $\mathbf{7 8}$ & 25.69 \\
Acinonyx jubatus & $\mathbf{7 8}$ & 23.40 \\
Tragelaphus strepsiceros & 77 & $\mathbf{2 9 . 1 0}$ \\
Mellivora capensis & 77 & 22.31
\end{tabular}


Genetta sp.

Phacochoerus africanus

Aepyceros melampus

Felis silvestris

Damaliscus pygargus

Giraffa camelopardalis

Syncerus caffer

Mungos mungo

Proteles cristatus

Rhabdomys pumilio

Tragelaphus scriptus

Ceratotherium simum

Equus burchelli

Elephantulus myurus

Hippotragus equinus

Cephalophus natalensis

Aethomys chrysophilus

Ichneumia albicauda

Connochaetes gnou

Otomys sp.

Redunca arundinum

Tragelaphus angasii

Neotragus moschatus

Genetta tigrina

Lepus capensis

Hystrix africaeaustralis

Diceros bicornis

Chlorocebus aethiops

Connochaetes taurinus

Raphicerus campestris

Equus zebra

Pelea capreolus

Oryx gazella

Damaliscus lunatus

Sylvicapra grimmia

Pedetes capensis

Antidorcas marsupialis

Procavia capensis

Pronolagus rupestris

Leptailurus serval

Potamochoerus larvatus

Redunca fulvorufula

Praomys sp.
60

58
20.71

15.39

14.69

25.84

16.08

14.40

14.40

18.57

15.31

23.98

12.34

12.05

10.60

20.30

9.72

7.85

10.91

11.00

9.62

8.85

6.48

6.15

5.82

11.14

8.89

8.13

7.12

6.68

5.65

5.65

5.80

14.58

7.70

4.60

4.60

16.15

15.40

12.86

12.86

9.45

5.82

14.29

4.39 


\begin{tabular}{lll} 
Oreotragus oreotragus & 58 & 2.21 \\
Otocyon megalotis & 57 & 6.56 \\
Galerella pulverulenta & 56 & 21.82 \\
Vulpes chama & 56 & 12.30 \\
Mastomys natalensis & 56 & 3.79 \\
Alcelaphus buselaphus & 56 & 2.27 \\
Suricata suricatta & 55 & 9.91 \\
Aethomys namaquensis & 54 & 4.53 \\
Lemniscomys rosalia & 54 & 4.53 \\
Mastomys coucha & 54 & 4.53 \\
Hippotragus niger & 54 & 2.92 \\
Raphicerus melanotis & 54 & 2.07 \\
Galerella sanguinea & 47 & 5.58 \\
Parahyaena brunnea & 47 & 1.79 \\
Atelerix frontalis & 46 & 4.77 \\
Rhynchogale melleri & 44 & 1.72 \\
Felis nigripes & 42 & 6.17 \\
Otolemur crassicaudatus & 42 & 0 \\
Soricidae & 39 & 0.18 \\
Otomys occidentalis & 35 & 0 \\
Tatera leucogaster & 35 & 0 \\
Elephantulus edwardii & 34 & 8.64 \\
Elephantulus brachyrhynchus & 34 & 0.04 \\
Saccostomus campestris & 21 & 1.22 \\
Cynictis penicillata & 19 & 0 \\
Genetta genetta & 19 & 0 \\
Ictonyx striatus & 17 & 0 \\
Papio hamadryas & 10 & 0 \\
Macroscelides proboscideus & 7 & 0 \\
Loxodonta africana & 2 & 0 \\
\hline
\end{tabular}

Appendix G. Node property values (degree and betweenness) of wild mammals sharing juvenile ticks. The most connected species in bold.

\begin{tabular}{lll}
\hline Wild mammal species sharing juvenile ticks & Degree & Betweenness \\
\hline Lepus saxatilis & $\mathbf{7 6}$ & $\mathbf{1 1 4 . 6 7}$ \\
Caracal caracal & $\mathbf{7 4}$ & $\mathbf{5 2 . 6 8}$ \\
Civettictis civetta & $\mathbf{7 4}$ & $\mathbf{4 6 . 3 9}$ \\
Acinonyx jubatus & $\mathbf{7 3}$ & $\mathbf{3 0 . 7 2}$ \\
Aepyceros melampus & $\mathbf{7 3}$ & $\mathbf{3 0 . 7 2}$ \\
Panthera leo & $\mathbf{7 3}$ & $\mathbf{3 0 . 7 2}$ \\
Canis mesomelas & $\mathbf{7 2}$ & $\mathbf{3 5 . 7 6}$ \\
Lycaon pictus & $\mathbf{7 2}$ & 25.15 \\
Panthera pardus & $\mathbf{7 2}$ & 25.15
\end{tabular}


Genetta sp. $\quad 70$

22.12

Mungos mungo

20.77

Crocuta crocuta

22.39

Felis silvestris

14.72

Tragelaphus scriptus

14.33

Cephalophus natalensis

13.89

Giraffa camelopardalis

13.21

Phacochoerus africanus

9.59

Taurotragus oryx

9.59

Tragelaphus angasii

9.59

Tragelaphus strepsiceros

9.59

Proteles cristatus

22.38

Ichneumia albicauda

12.77

Redunca arundinum

Syncerus caffer

8.56

Elephantulus myurus

8.56

Rhabdomys pumilio

Neotragus moschatus

21.74

63

26.80

Connochaetes taurinus

7.27

Equus burchelli

6.42

Raphicerus campestris

6.42

Damaliscus pygargus

Genetta tigrina

6.42

61

9.73

Damaliscus lunatus

Hippotragus equinus

Mellivora capensis

Sylvicapra grimmia

Otomys sp.

Chlorocebus aethiops

6.28

61

5.51

61

5.51

61

5.51

61

5.51

60

15.40

60

10.33

Lepus capensis

13.99

Procavia capensis

12.74

Pronolagus rupestris

Oreotragus oreotragus

12.74

Pedetes capensis

Aethomys chrysophilus

17.95

57

17.09

Praomys sp.

7.96

Pelea capreolus

2.86

Antidorcas marsupialis

8.39

Connochaetes gnou

8.39

Redunca fulvorufula

8.39

Alcelaphus buselaphus

3.10

Mastomys natalensis

Raphicerus melanotis

9.83

53

2.65 


\begin{tabular}{|c|c|c|}
\hline Otocyon megalotis & 52 & 13.77 \\
\hline Equus zebra & 52 & 1.57 \\
\hline Oryx gazella & 52 & 1.57 \\
\hline Ceratotherium simum & 47 & 1.18 \\
\hline Suricata suricatta & 47 & 0.76 \\
\hline Potamochoerus larvatus & 46 & 0.61 \\
\hline Galerella pulverulenta & 44 & 5.56 \\
\hline Diceros bicornis & 44 & 0.19 \\
\hline Leptailurus serval & 42 & 0 \\
\hline Otolemur crassicaudatus & 42 & 0 \\
\hline Rhynchogale melleri & 39 & 2.85 \\
\hline Atelerix frontalis & 39 & 0 \\
\hline Hystrix africaeaustralis & 39 & 0 \\
\hline Galerella sanguinea & 38 & 0.39 \\
\hline Soricidae & 35 & 0.18 \\
\hline Aethomys namaquensis & 32 & 3.68 \\
\hline Lemniscomys rosalia & 32 & 3.68 \\
\hline Mastomys coucha & 32 & 3.68 \\
\hline Vulpes chama & 27 & 3.30 \\
\hline Otomys occidentalis & 19 & 0 \\
\hline Tatera leucogaster & 19 & 0 \\
\hline Elephantulus edwardii & 18 & 9.67 \\
\hline Elephantulus brachyrhynchus & 14 & 0.02 \\
\hline Saccostomus campestris & 13 & 0.06 \\
\hline Ictonyx striatus & 7 & 0 \\
\hline Macroscelides proboscideus & 2 & 0 \\
\hline
\end{tabular}

Appendix H. Node property values (degree and betweenness) of wild mammals sharing adult ticks. The most connected species in bold.

\begin{tabular}{lll}
\hline Wild mammal species sharing adult ticks & Degree & Betweenness \\
\hline Panthera pardus & $\mathbf{6 2}$ & $\mathbf{9 2 . 8 9}$ \\
Panthera leo & $\mathbf{6 2}$ & $\mathbf{8 1 . 1 2}$ \\
Lepus saxatilis & $\mathbf{6 0}$ & $\mathbf{1 3 6 . 4 8}$ \\
Acinonyx jubatus & $\mathbf{5 8}$ & $\mathbf{6 0 . 0 5}$ \\
Mellivora capensis & $\mathbf{5 6}$ & $\mathbf{5 0 . 9 6}$ \\
Caracal caracal & $\mathbf{5 5}$ & $\mathbf{5 6 . 5 4}$ \\
Canis mesomelas & $\mathbf{5 3}$ & $\mathbf{6 1 . 3 5}$ \\
Lycaon pictus & $\mathbf{5 1}$ & $\mathbf{4 6 . 0 6}$ \\
Crocuta crocuta & $\mathbf{5 1}$ & $\mathbf{4 3 . 5 2}$ \\
Civettictis civetta & $\mathbf{5 0}$ & 42.06 \\
Taurotragus oryx & $\mathbf{5 0}$ & 24.46 \\
Tragelaphus strepsiceros & $\mathbf{5 0}$ & 24.46 \\
Giraffa camelopardalis & 48 & 18.83
\end{tabular}


Damaliscus pygargus

Phacochoerus africanus

9.13

Syncerus caffer

Equus burchelli

Hippotragus equinus

Ceratotherium simum

Tragelaphus angasii

Aepyceros melampus

Connochaetes taurinus

Vulpes chama

Connochaetes gnou

Tragelaphus scriptus

Damaliscus lunatus

Redunca arundinum

Felis silvestris

Leptailurus serval

Diceros bicornis

Equus zebra 22.82

Genetta sp. 18.95

Oryx gazella

5.13

Potamochoerus larvatus

3.82

Raphicerus campestris

3.32

Redunca fulvorufula

9.62

Antidorcas marsupialis

4.09

Pelea capreolus

4.72

Hippotragus niger

1.59

Proteles cristatus

7.29

Hystrix africaeaustralis

1.72

Procavia capensis 18.83

Parahyaena brunnea

Felis nigripes

8.33

31

9.46

Sylvicapra grimmia

30

1.33

Alcelaphus buselaphus

30

30

0.39

Cephalophus natalensis

10.51

Galerella pulverulenta

Suricata suricatta

Oreotragus oreotragus

Neotragus moschatus

Atelerix frontalis

Cynictis penicillata

Galerella sanguinea

Genetta genetta

19

Genetta tigrina 


\begin{tabular}{lll} 
Mungos mungo & 19 & 0 \\
Elephantulus myurus & 17 & $\mathbf{7 6 . 1 3}$ \\
Lepus capensis & 17 & 5.71 \\
Ichneumia albicauda & 17 & 0 \\
Ictonyx striatus & 17 & 0 \\
Otocyon megalotis & 17 & 0 \\
Raphicerus melanotis & 15 & 0.07 \\
Pedetes capensis & 15 & 0 \\
Rhabdomys pumilio & 15 & 0 \\
Pronolagus rupestris & 5 & 0.41 \\
Papio hamadryas & 3 & 0 \\
Otomys sp. & 1 & 0 \\
\hline
\end{tabular}

